\title{
EVALUATION METHODOLOGY FOR ENERGY EFFICIENCY OF AIR CONDITIONERS IN THAILAND
}

\author{
MALEE SANTIKUNAPORN ${ }^{1}$, PRAPAT WANGSKARN ${ }^{1} \&$ CHANNARONG ASAVATESANUPAP ${ }^{2}$ \\ ${ }^{1}$ Department of Chemical Engineering, Faculty of Engineering, Thammasat University, Thailand \\ ${ }^{2}$ Department of Mechanical Engineering, Faculty of Engineering, Thammasat University, Thailand
}

\begin{abstract}
Energy efficiency standard and labelling system (EES\&L) is an important policy that needs to be strengthened in order for a country to achieve long-term energy security. Air conditioners are considered to be the appliance in the residential sector which consumes the largest amount of energy. Therefore, in order for policymakers to develop long-term plans an effective evaluation method needs to be developed in order to accurately represent energy savings that occur from implementation of the EES\&L. Two different types of evaluation methods were investigated based on energy efficiency of air conditioners after implementation of the EES\&L including Label No. 5 by EGAT and mandatory standards by TISI. The two evaluation methods were the Top-down and Bottom-up approaches. Results from the study showed a significant difference in the total energy saving obtained through the Topdown and Bottom-up approaches. Application of the labelling system was observed to cause an improvement in energy efficiency of air conditioners by $30 \%$.
\end{abstract}

Keywords: energy efficiency, air conditioners.

\section{INTRODUCTION}

Energy security is an important issue that has attracted a lot of attention for the past decade due to the shortage in petroleum oil accompanied by expansion of the economy. In response, government around the world are considering policies to implement alternative sources of energy, such as biofuel, biogas, solar cell and wind turbine. However, if energy consumption is not controlled or energy is not being used efficiently then it is very difficult to meet rapid growing demand of the future generation. Therefore, in addition to finding a replacement for petroleum oil, it is important for the government to promote efficient usage of energy as well. Among many different measures issued to support efficient energy usage in Thailand, the Energy Efficiency Standard and Labelling (EES\&L). According to a study conducted in 2005, an increase in both the average energy efficiency and the number of energy efficient equipment were observed after implementation of the labelling system [1].

Three main agencies that are responsible for EES\&L including the Thai Industrial Standards Institute (TISI), Department of Alternative Energy Development and Efficiency (DEDE), and the Electricity Generating Authority of Thailand (EGAT) [2]. In general, DEDE's main role is to promote EES\&L and determine the Minimum Energy Performance Standards (MEPS) and High Energy Performance Standards (HEPS). MEPS is regulated by TISI and it is employed to classify group of equipment with low energy efficiency. On the other hand, HEPS is used for equipment with energy efficiency that is higher than the average. The purpose of a HEPS is to inform consumer of the superior energy efficiency of the equipment. Another important labelling type in Thailand is the Energy Label No.5 label, which is validated and granted by EGAT. Currently, all three measures are voluntary, which mean that it is up to the equipment manufactures and exporters to decide whether or not to apply for a label. Unfortunately, these voluntary labelling systems were found to be ineffective because most equipment in the market has low energy efficiency, but consumers still buy due to lower price. Consequently, TISI began to create and regulate another standard 
known as ISO which is currently a mandatory measure for many different type of equipment including air conditioners and refrigerators.

Electricity consumption in Thailand is divided into three main sources including industrial, residential and commercial sector. According to EGAT, equipment that consume the majority of electricity in residential sector included air conditioners $(46 \%)$ and refrigerators $(17 \%)$. An air conditioner defined by DEDE is a device that released heat from a room, which consisted of a condensing unit and a Fan-coil unit that is operated via an alternating current at $50 \mathrm{~Hz}$. As mentioned previously due to an increase in awareness for energy security, air conditioner manufacturer can apply for voluntary labelling Label No. 5 (issued by EGAT) and mandatory labelling that is issued by TISI. However, it is also very important to create an evaluation method which can accurately represent the effectiveness of each labelling systems mentioned previously. Two approaches that have been frequently employed for evaluation of energy efficiency from implementation of different policies included top-down and bottom-up approaches. Top-down approach is defined as an evaluation method that calculate energy efficiency based on data acquired in a national scale. On the other hand, bottom-up approach is defined as a calculating method that uses data collected from issuance of measures. Therefore, a bottom-up approach would give more information on the concept, process and detail leading to an effective evaluation of the energy efficiency.

This study aims to evaluate the effectiveness of the energy labelling system program (Label No. 5 by EGAT and mandatory standards by TISI) for air conditioners in Thailand. Additionally, comparison between the top-down and bottom-up approach for calculating the energy efficiency will also be investigated.

\section{METHODS}

\subsection{Top-down approach}

Energy efficiency is defined as the ratio between the net heat removal by air conditioners and the rate power input. According to eqn (1), net heat removal is defined as the overall ability of an air conditioner to remove both sensible and latent heat from the designated area. Rated power input is defined as the power required to operate gas pump, ventilation, control system and other devices inside a functional air conditioner. The energy saving potential is therefore calculated by using the generic equation shown in eqn (2).

$$
\begin{gathered}
E E R=\frac{\text { Net heat removal by air conditioner }(W r)}{\text { Rated power input }(W)} \\
\Delta E_{a c}=P_{a c} \times\left(\frac{1}{E E R}\right) \times h \times d,
\end{gathered}
$$

Top-down approach is an evaluation method that uses national data such as the total number of air conditioners sold in a specific year. The energy saving potential is therefore the difference between the average energy efficiency and the high energy efficiency multiplied by the operating hour cooling capacity and the operating day per year as shown in eqn (3). The total annual energy saving is calculated by multiplying the value obtained in eqn (1) (energy saving potential) by the total number of air conditioners sold in a specific year as shown in eqn (4). 


$$
\Delta E_{a c}=P_{a c} \times\left(\frac{1}{A_{a c}}-\frac{1}{H_{a c}}\right) \times h \times d
$$

where $\Delta E_{a c}$ is the Energy saving potential of air conditioner per unit per year (Wh/year), $P_{a c}$ is the cooling capacity $(\mathrm{Wr}), H_{a c}$ is the high energy efficiency $(\mathrm{Wr} / \mathrm{W}), A_{a c}$ is the average energy efficiency $(\mathrm{Wr} / \mathrm{W}), h$ is operating hour, and $d$ is operating day per year.

$$
E_{T D}=\Delta E_{a c} \times N_{T}
$$

where $E_{T D}$ is the total energy saving in a specific year (GWh/year) calculated using the Topdown approach and $N_{T}$ is the total number of air conditioners sold in a specific year.

\subsection{Bottom-up approach}

For bottom-up approach the evaluation sequence also begin by calculating the energy saving potential using eqn (1). However, for the bottom-up approach the total annual energy saving in a specific year is calculated as the differences between the energy saving potential from the business as usual (BAU) mode and from the efficient case (EFF) mode. The BAU mode represent baseline where energy saving is calculated from normal standard for energy efficiency. Therefore, the energy saving potential of air conditioners $\left(\Delta E_{a c, B A U}\right)$ per unit per year is calculated considering business as usual (BAU) mode, which is not influenced by any energy saving regulation as shown in eqn (5). On the other hand, the EFF mode represent the optimum energy efficient standard such as Label No. 5 as shown in eqn (6). The total annual energy saving from the Bottom-up approach is therefore calculated using eqn (7).

$$
\Delta E_{a c, B A U}=P_{a c} \times\left(\frac{1}{E E R_{M E P S}}\right) \times h \times d,
$$

where $E E R_{M E P S}$ is the energy efficient ratio calculated from air conditioners that belong to the Minimum Energy Performance Standard (MEPS).

$$
\Delta E_{a c, E E F}=\left(\frac{P_{a c}}{E E R_{A, L 5}}\right) \times h \times d
$$

where $\Delta E_{a c, E F F}$ is the energy saving potential of air conditioners per unit per year calculated considering the efficient case (EFF) mode, which is not influenced by any energy saving regulation. $E E R_{A, L 5}$ is the energy efficient ratio calculated from devices that have Energy saving label No. 5 .

$$
E_{B U}=\left(\Delta E_{B A U}-\Delta E_{E F F}\right) \times N_{L 5} .
$$

\section{RESULTS AND DISCUSSION}

Energy saving from Top-down approach was calculated based on the total number of air conditioners sold from 2010 to 2017, as shown in Table 1. Data during 2010 to 2013 were obtained from DEDE's project for drafting of regulation for machinery and equipment for energy efficiency and standard for minimum Energy Efficiency to preserve energy [3]. Information from year 2014 to 2017 were found from the study of policy for labeling product or energy efficient product in Thailand. The values that are used to calculate energy saving potential are demonstrated in Table 2. The total energy saving from 2010 to 2017 is calculated 
by multiplying the number of air conditioners sold with the energy saving potential found by using eqn (3) and eqn (4).

Table 1: Number of air conditioners sold from 2010 to 2017.

\begin{tabular}{|c|c|c|c|c|c|c|c|c|}
\hline \multirow{2}{*}{$\begin{array}{c}\text { Cooling } \\
\text { capacity } \\
(\mathrm{Wr})\end{array}$} & \multicolumn{7}{|c|}{ Number of air conditioners sold per year (in million units) } \\
\cline { 2 - 9 } & 2010 & 2011 & 2012 \\
{$[3]$} & 2013 & 2014 & 2015 & 2016 & 2017 \\
{$[3]$} & {$[3]$} & {$[4]$} & {$[4]$} & {$[4]$} \\
\hline$<8,000$ & 0.798 & 0.918 & 1.048 & 1.114 & 1.214 & 1.326 & 1.429 & 1.524 \\
\hline $\begin{array}{c}8,000- \\
12,000\end{array}$ & 0.074 & 0.085 & 0.098 & 0.103 & 0.113 & 0.123 & 0.133 & 0.141 \\
\hline Total & 0.872 & 1.003 & 1.146 & 1.217 & 1.327 & 1.449 & 1.562 & 1.665 \\
\hline
\end{tabular}

Table 2: Data used in calculations using Top-down approach.

\begin{tabular}{|c|c|c|c|c|c|}
\hline \multirow{2}{*}{$\begin{array}{c}\text { Cooling } \\
\text { capacity } \\
(\mathrm{Wr})\end{array}$} & \multirow{2}{*}{$\begin{array}{c}\text { Average } \\
\text { capacity; } \\
\mathrm{P}_{\mathrm{ac}} \\
(\mathrm{Wr})\end{array}$} & \multicolumn{2}{|c|}{$\begin{array}{l}\text { Energy efficiency } \\
(\mathrm{Wr} / \mathrm{W})\end{array}$} & \multirow{2}{*}{$\begin{array}{c}\text { Average } \\
\text { hour per day } \\
\text { (h) }\end{array}$} & \multirow{2}{*}{$\begin{array}{c}\text { Average day } \\
\text { per year } \\
\text { (d) }\end{array}$} \\
\hline & & $\begin{array}{c}\text { Average } \\
\text { efficiency; } \\
\mathrm{A}_{\mathrm{ac}} \\
\end{array}$ & $\begin{array}{c}\text { High } \\
\text { efficiency; } \\
\mathrm{H}_{\mathrm{ac}} \\
\end{array}$ & & \\
\hline$<8,000$ & 4,500 & 3.33 & 3.93 & 10.65 & 305 \\
\hline $\begin{array}{l}8000- \\
12,000\end{array}$ & 10,200 & 3.33 & 3.93 & 10.65 & 305 \\
\hline
\end{tabular}

Table 3: Total annual energy savings using Top-down approach.

\begin{tabular}{|c|c|c|c|c|c|c|c|c|}
\hline \multirow{2}{*}{$\begin{array}{c}\text { Cooling } \\
\text { capacity } \\
(\mathrm{Wr})\end{array}$} & 2010 & 2011 & 2012 & 2013 & 2014 & 2015 & 2016 & 2017 \\
\cline { 2 - 9 } & 534.6 & 615.4 & 702.5 & 746.5 & 813.8 & 888.5 & 957.7 & $1,021.1$ \\
\hline$<8,000$ & 53.5 & 129.5 & 147.9 & 157.2 & 171.3 & 187.1 & 201.6 & 215.0 \\
\hline $\begin{array}{c}8,000- \\
12,000\end{array}$ & 112.6 & 12.0 & 740.4 & 903.7 & 985.1 & $1,075.6$ & $1,159.3$ & $1,236.1$ \\
\hline Total & 647.4 & 744.9 & 850.4 & & & & & \\
\hline
\end{tabular}

For the Bottom-up approach, the total number of Label No. 5 issued was used to calculate the total energy saving [5]. The average energy efficiency for air conditioners in Table 4 was 
obtained from equipment testing conducted by the Institute of Electricity and Electronic. Information regarding the operating hour per day and the operating day per week were used according to calculations from EGAT [6]. The total energy saving per year were found by calculating the difference between energy saving potential from BAU and EFF mode. The BAU mode used energy efficiency of equipment in the category of MEPS, which was labelled by TISI. As shown in Table 5 the MEPS for air conditioners is $2.82 \mathrm{Wr} / \mathrm{W}$. For the EFF mode the energy efficiency used was from an averaged obtained by a Label No. 5 equipment which is considerable higher than the energy efficiency of HEPS equipment. After calculating the difference between energy saving from BAU and EFF mode the number is then multiply by the amount of Label No. 5 that was granted by EGAT per year. Table 6 shows the total energy saving that can be achieved be year according to the Bottom-up approach.

The difference in the total annual energy saving calculated by Top-down and Bottom approach are significant, as shown in Table 3 and Table 6 . The reason is that the information on the amount of equipment sold and label issues are an important factor in determining the energy saving potential. For the Top-down approach data were acquired in a national level, in this case from air conditioner manufacturers and vendors. Consequently, these number may not be as accurate because it is possible for manufacturers and vendors to be missed out on the information inquiry stage. Additionally, some manufacturers might not reveal the necessary data due to confidentiality. Therefore, most data were obtained indirectly from the revenue earned, which is submitted by the Ministry of Commerce.

Table 4: Number of Label No. 5 issued for air conditioners from 2007 to 2013.

\begin{tabular}{|c|c|c|c|c|c|c|c|}
\hline \multirow{2}{*}{$\begin{array}{c}\text { Cooling } \\
\text { capacity } \\
(\mathrm{Wr})\end{array}$} & 2007 & 2008 & 2009 & 2010 & 2011 & 2012 & 2013 \\
\cline { 2 - 8 } & 1.077 & 1.050 & 1.223 & 2.110 & 1.730 & 2.138 & 2.037 \\
\hline$<8,000$ & 0.054 & 0.043 & 0.060 & 0.116 & 0.110 & 0.106 & 0.125 \\
\hline $8,000-$ \\
12,000
\end{tabular}

Table 5: Data used in calculations using Bottom-up approach.

\begin{tabular}{|c|c|c|c|c|c|c|c|}
\hline \multirow{2}{*}{$\begin{array}{c}\text { Cooling } \\
\text { capacity } \\
(\mathrm{Wr})\end{array}$} & \multirow{2}{*}{$\begin{array}{c}\text { Average } \\
\text { capacity; } \mathrm{P}_{\mathrm{ac}} \\
(\mathrm{Wr})\end{array}$} & \multicolumn{4}{|c|}{$\begin{array}{l}\text { Energy efficiency } \\
\qquad(\mathrm{Wr} / \mathrm{W})\end{array}$} & \multirow{2}{*}{$\begin{array}{c}\text { Average } \\
\text { hour per } \\
\text { day } \\
\text { (h) }\end{array}$} & \multirow{2}{*}{$\begin{array}{c}\text { Average } \\
\text { day per } \\
\text { year } \\
\text { (d) }\end{array}$} \\
\hline & & $\begin{array}{l}\text { MEPS } \\
(T I S I)^{[7]}\end{array}$ & $\begin{array}{c}\text { HEPS } \\
(\mathrm{DEDE})^{[8]}\end{array}$ & $\begin{array}{c}\text { Label } \\
\text { No.5 } \\
\text { (EGAT) }^{[9]}\end{array}$ & $\begin{array}{c}\text { Average } \\
\text { from Label } \\
\text { No. } 5^{[5]}\end{array}$ & & \\
\hline$<8,000$ & 5,050 & 2.82 & 3.22 & 3.40 & 3.51 & 8 & 365 \\
\hline $\begin{array}{l}8000- \\
12,000\end{array}$ & 10,023 & 2.82 & 3.22 & 3.22 & 3.36 & 8 & 365 \\
\hline
\end{tabular}


Table 6: Total annual energy savings using Bottom-up approach.

\begin{tabular}{|c|c|c|c|c|c|c|c|}
\hline \multirow{2}{*}{$\begin{array}{c}\text { Cooling } \\
\text { capacity } \\
(\mathrm{Wr})\end{array}$} & \multicolumn{7}{|c|}{ Total annual energy savings (GWh) } \\
\cline { 2 - 8 } & 2007 & 2008 & 2009 & 2010 & 2011 & 2012 & 2013 \\
\hline$<8,000$ & $1,100.5$ & $1,072.9$ & $1,249.7$ & 2,156 & $1,767.7$ & $2,184.6$ & $2,081.4$ \\
\hline $\begin{array}{c}8,000- \\
12,000\end{array}$ & 90.1 & 71.7 & 100.1 & 193.5 & 183.5 & 176.8 & 208.5 \\
\hline Total & $1,190.6$ & $1,144.6$ & $1,349.8$ & $2,349.5$ & $1,951.2$ & $2,361.4$ & $2,289.9$ \\
\hline
\end{tabular}

On the other hand, the Bottom-up approach uses the number of Label No. 5 that are issued for air conditioners in each year. This seems to be more reliable, however, the information received may not be accurate because some air conditioners that receive Label No. 5 may be exported to other countries in the ASEAN community. Additionally, it is not very likely for all the air conditioners that received Label No. 5 to be sold in the same year. Some of these air conditioners may be sold in the next year. Currently, approximately $80 \%$ of the air conditioners in Thailand have already received Label No. 5. Energy efficiency increased by $30 \%$ due to implementation of the labeling system.

\section{CONCLUSION}

Evaluation of energy saving policy is an important part of developing a nation with energy security. The Top-down and Bottom-up approach were used to evaluate the effectiveness of energy standards and Label No. 5 system for air conditioners in Thailand. Results show a significant difference in the total energy saving calculated from each approach. There are advantages and disadvantages of apply both kind of approach. Top-down approach underestimate the total energy saving because this approach obtained most of the data from an indirect sources. On the other hand, the Bottom-up approach overestimate the total energy saving because some air conditioners that received Label No.5 may be exported to other countries in the ASEAM community.

\section{ACKNOWLEDGEMENT}

The authors would like to thank Faculty of Engineering, Thammasat University for financial support.

\section{REFERENCES}

[1] McMahon, S.W., Energy-efficiency labels and standards: A guidebook for appliances, equipment, and lighting., Collaborative Labelling and Appliance Standards Program, Washington, D.C., 2001.

[2] Lessons Learned Report on Energy Standards \& Labelling (ES\&L) Implementation in Thailand; Thailand Greenhouse Gas Management Organization (Public Organization)

[3] Online, http://bresl.tgo.or.th/download/report/Thailand_Report_Act_4_2.pdf Accessed on 20 Jul. 2017.

[4] Draft regulation for Machinery and Equipment for Energy Efficiency and Standard for Minimum Energy Efficiency to preserve energy, in, Bangkok, 2013. 
[5] The study of policy for labelling product or energy efficient product in Thailand, in, Bangkok, 2014.

[6] Review of Energy Efficiency Standard for Product in the Announcement from Ministerial Regulations in, Department of Alternative Energy Department and Efficiency, Bangkok, 2013.

[7] Air Conditioner No. 5, in, Electricity Generating Authority Thailand.

[8] Notifications of Ministry of Industry Issue 4315 (BE 2554) from the Standard in Industry Act BE 2511 on Cancellation of standard and regulation of Standard for Industrialized Products Air Conditioners for a room : Energy Efficiency, in, Royal Thai Government Gazette, p. 7, 2011.

[9] Notifications of Ministry of Industry on Setting Energy Efficiency Value, Institute for testing Energy Efficiency Standard and Method for Testing to Obtain Energy Efficient Value for High Efficient Air Conditioners BE 2552), in, Royal Thai Government Gazette, pp. 50-51, 2010.

[10] Manual for Energy Saving Label No.5 for Air Conditioners, in, Electricity Generating Authority of Thailand, Nonthaburi, 2012. 